\title{
Development of Aluminium Based Mango Seed Mangiferaindica Shell Ash (MSSA) Particulate Metal Matrix Composite
}

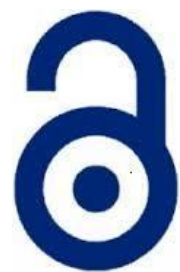 \\ Received: 11 March 2021 \\ Accepted: 11 May 2021 \\ Published: 15 July 2021 \\ Publisher: Deer Hill Publications \\ (c) 2021 The Author(s) \\ Creative Commons: CC BY 4.0
}

Ochuokpa E. O, Yawas, D. S., Sumaila, M. and Adebisi A. A.

\begin{abstract}
A composite material is a combination of two or more chemically distinct and insoluble phases; its properties and structural performance are superior to those of the constituents acting independently. MMCs are made by dispersing a reinforcing material into a metal matrix to improve their properties. They are prepared by powder metallurgy and casting, although several technical challenges exist with casting technology. Achieving a homogeneous distribution of reinforcement within the matrix is one such challenge, and this affects directly on the properties and quality of composite. In this work a composite is developed by adding Mango seed shell Ash (MSSA) particulate in Al- Si-Mg Alloy by mass ratio $5 \%, 10 \%, 15 \%$ and $20 \%$. The composite was prepared by stir casting technique. It is proposed to use this material for production of motorcycle wheel hub which are subjected to continuous wear as the hubs are in direct contact with the brakes and rotating sprockets. The MSSA, was characterized using X-ray fluorescent (XRF). The result reveals $\mathrm{SiO}_{2}$, has the highest percentage composition followed by $\mathrm{CaO}, \mathrm{Al}_{2} \mathrm{O}_{3}, \mathrm{Fe}_{2} \mathrm{O}_{3}$ and $\mathrm{Mg} \mathrm{O}_{2}$ as major phases. The presents of these hard constituent compounds suggests that the mango seed shell ash can be used as particulate reinforcement in various metal matrices since the chemical composition has similarity with the XRF analysis of Periwinkle shell ash, rice husk, fly ash, and bagasse ash currently used in metal matrix composite. Mechanical tests such as hardness test and impact test were conducted. The results revealed that increase in the percentage of MSSA progressively increased the hardness of the material from $5 \%$ wt to a maximum hardness of $43.2 \mathrm{HV}$ at $15 \%$ addition of MSSA. This represents a $26.16 \%$ improvement over the unreinforced alloy. However, the impact energy progressively decreases of the material from 5\%wt of MSSA and later increased to optimum energy at $15 \%$ addition of MSSA. From the results it is concluded that composite material such as Al- Si-Mg/ MSSA is one of the options as a material for production of motorcycle hub. The wear test of the composite was then carried out using Taguchi design to optimize the range of MSSA from $5 \%$ wt $-15 \%$ wt., Sliding speed of $5 \mathrm{~cm} / \mathrm{s}-20 \mathrm{~cm} / \mathrm{s}$, sliding distance from $50 \mathrm{~m}$ to $200 \mathrm{~m}$, and the load of $2 \mathrm{~N}, 4 \mathrm{~N}, 6 \mathrm{~N}, \& 8 \mathrm{~N}$ respectively. Analysis of the result of $\mathrm{SN}$ ratio for wear rate shows the optimum wear resistant value is in the combination of Load $=4 \mathrm{~N}$, sliding speed $=10 \mathrm{~cm} / \mathrm{s}$ sliding distance $=200 \mathrm{~m}$ and MSSA $=15 \mathrm{wt} \%$ These also correspond with the analysis of wear maps \& wear rate presented in the diagrams of dynamic friction coefficient (COF) for Al-Si- Mg/ MSSA Composite.
\end{abstract}

Keywords: Aluminium Metal Matrix composite, Stir Casting, Mango Seed Shell Ash, motorcycle hub.

\section{INTRODUCTION}

The desire to develop a composite material using Mango seed shell Ash (MSSA) to reinforce the conventional motorcycle hub was prompted by the fact that the motorcycles usually referred to as "Okada" in Nigeria have become a popular mode of transportation, The hubs are in direct contact with the brakes and rotating sprockets hence they are subject to frequent mechanical failure due to wear as a result bad road. They are therefore in high demand for replacement. Similarly, there are large quantities of mango seeds discarded as waste on the streets across Nigerian rural communities after consumption of the mango fruits constituting environmental hazards to the public.

The local content policy of Nigerian government in recent times has stimulated great interest in the utilization of abundant agricultural waste for in production of engineering materials. Agricultural waste products such as Mellon shell, eggshell, sugarcane, bagasse, rice husk, coconut shell, bamboo leaf, ground nutshell and other organic waste have been successfully used for Aluminium alloy particulate composite reinforcement [1], This is in line with the global

Ochuokpa E. O' ${ }^{1}$ Yawas, D. S. ${ }^{2}$, Sumaila, M. ${ }^{2}$ and Adebisi A.A A $^{1,3}$

'Department of Metallurgical and Materials Engineering, Ahmadu Bello University, Zaria, Nigeria

2Department of Mechanical Engineering, Ahmadu Bello University, Zaria, Nigeria

3Department of Metallurgical and Materials Engineering, Air Force Institute of Technology, Kaduna, Nigeria

E-mail: dyawas@yahoo.com 
demand for the development of advanced engineering materials for various engineering applications in modern times [2]. However, to the best of our knowledge, no work has been done on the use of abundant mango 'Mangiferaindica' seed shell ash (MSSA) as reinforcement for aluminium matrix. This research therefore provides pioneering knowledge on the possibility of using mango seed shell as reinforcement for aluminium matrix composites (AMCs) for production of automobile component and other engineering applications. It is expected to reduce the high cost of the Synthetic reinforcements of AMCs such as silicon carbide $(\mathrm{SiC})$ and alumina $\left(\mathrm{Al}_{2} \mathrm{O}_{3}\right)$ which are imported at high foreign currency exchange rate in Nigeria Leading to high cost of production of motorcycle wheel hubs.

There are some micro structural features that limit mechanical properties of cast $\mathrm{Al}-\mathrm{Si}$ - Mg alloys such as Porosity, coarse acicular Si particles and coarse primary aluminium dendrites [3]. Similarly, the presence of $\mathrm{Mg}$ and Fe in the alloy gives an opportunity for the formation of eutectic $\alpha+\mathrm{Mg}_{2} \mathrm{Si}$ and platelets of $\mathrm{Fe}_{2} \mathrm{Si}_{2} \mathrm{Al}_{9}$ in addition to the $\mathrm{Si}$ platelets. These plate-shaped phases provide easy crack nucleation sites and propagation paths, resulting in relative low strengths and ductility [4].

Motorcycle hub is in direct contact with the brakes and rotating sprockets hence it is subject to frequent mechanical failure. The main extent and reason for their failures include surface fatigue wear caused by fracture and breakages as a result of direct contact with the brakes and rotating sprockets, bad road and gallops, and poor quality of spares. After consumption of the mango fruits, a large quantity of mango seeds is discarded as waste in Nigeria constituting environmental hazards to the general public. This research is aimed at developing aluminium based Mango Seed Mangiferaindica Shell Ash (MSSA) particulate metal matrix composite for engineering application. To the best of our knowledge, no previous work has been done on the use of abundant mango seed shell as in the reinforcement of $\mathrm{Al}$ Matrix composites (AMCs) for engineering applications. This study will therefore provide pioneering knowledge on the possibility of using mango seed shell Ash (MSSA) as reinforcement for AMCs for spare parts production. It will also succeed in creating employment opportunities in Nigeria by converting agro-waste product to wealth and positively influence the economy. It will help solve the environmental problems caused by the overwhelming quantity of agro-waste disposal challenges in Nigeria.

\section{LITERATURE REVIEW}

\subsection{Aluminium Alloying Elements}

The typical alloying elements added to aluminium are Zinc (Zn), Copper (Cu), Silicon (Si), Iron (Fe), magnesium $(\mathrm{Mg})$, Lithium ( $\mathrm{Li})$. Manganese (Mn), Nickel (Ni) and Tin (Ti) [5]. Because of their varying solid solubility, some are used as solid solution while others are added to form various desirable intermetallic compounds.

\subsection{Materials for Motorcycle Hubs}

Mostly, Aluminium motorcycle hubs are products of aluminium- magnesium alloys because of their unique casting properties, good resistance to corrosion, easy to cast into thin or thick sections, excellent machinability, and good strength to weight ratio [6].

\subsubsection{Al-Si-Mg Alloy}

An alloy of Al-Si-Mg has wide application in automotive and aerospace industry due to their excellent castability and a high strength-to-weight ratio [7].

\subsubsection{Aluminium Oxide}

$\mathrm{Al}_{2} \mathrm{O}_{3}$, is known to be stable in aluminium, but it reacts with magnesium in aluminium alloys containing $\mathrm{Mg}$ to form $\mathrm{Mgo}$ and $\mathrm{MgAl}_{2} \mathrm{O}_{4}$. (spinel) as shown in the following equations. $\mathrm{MgO}$ may form at high magnesium level and lower temperature whereas the spinel will form even at very low magnesium levels [8]. This explains why $\mathrm{Al}_{2} \mathrm{O}_{3}$ is not thermodynamically stable in most aluminium alloys.

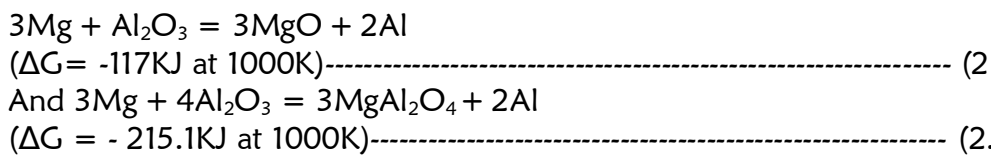

\subsection{The Role of Magnesium}

Improvement of wettability between the Al-Mg-Si alloy and the reinforcements. Magnesium and magnesium alloys are amongst the lightest materials for practical use as the matrix phase in metal matrix composites. When compared to other available structural materials, Magnesium is attractive because of its unique combination of low density and excellent machinability.

The role of Silicon alloy; The role of silicon is for casting flowability. For foundry production of castings, contain amounts of silicon far more than the amount that is soluble or needed for strengthening alone are required [9]. The function here is chiefly to improve casting soundness and freedom from cracking, but the excess silicon also serves to increase wear resistance. Aluminium alloys that are used for wear resistance application base on aluminium silicon alloy system [10]. Aluminium casting alloys must contain enough amount of silicon which is a eutectic- forming element, this is to enhance adequate fluidity to fill the shrinkage that usually occur during casting. 


\subsection{Defects in Al-Si-Mg Alloy}

The coarse acicular Si particles and coarse primary aluminium dendrites are bound to negatively affect the hardness properties of Al-Si-Mg alloy in production of motorcycle hub [11]. There is possibility of improving the properties of this alloy by the use of agro waste 'mango seed shell ash' as reinforcement hence the need to study the use of mango seed shell ash. There are three micro structural features that limit mechanical properties of cast Al- alloys such as ductility, toughness and fatigue resistance: Porosity, coarse acicular Si particles and coarse primary aluminium dendrites [9].

\subsection{Description of Motorcycle Wheel Hub}

The wheel rims are usually steel or aluminium generally with steel spokes and an aluminium hub. The rear motorcycle hub is at the central part of a motorcycle wheel that rotates on or with the axle and from which spokes radiates. It is in direct contact with the brakes and rotating sprockets hence it is subject to frequent Mechanical failure.

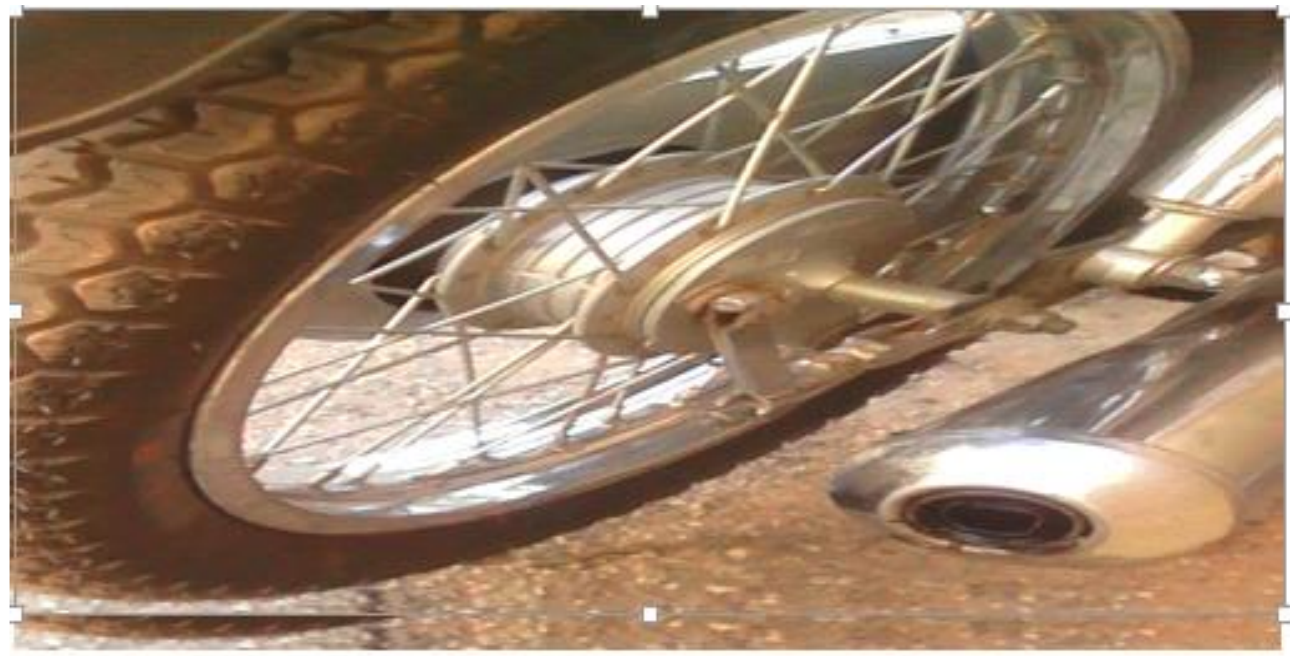

Figure 1: The rear motorcycle wheel hub

\subsection{Classification of Composite Materials}

Based on the type of matrix, composites are classified into the followings:

Metal matrix composites, Polymer matrix composites, Ceramic matrix composites, Carbon-Carbon composites, and hybrid composites.

\subsection{Benefits of Composite Materials}

In the recent past, materials development has shifted from monolithic to composite materials for adjusting to the global need for reduced weight, low cost, quality, and high performance in structural materials. Driving force for the utilization of Aluminium matrix composites (AMCs) in areas of aerospace and automotive industries include performance, economic and environmental benefits [12]. The conventional monolithic materials have limitations in achieving good combinations of strength, stiffness, toughness and density. Metal matrix composites (MMCs) possess significantly improved properties including high specific strength; specific modulus, damping capacity and good wear resistance compared to unreinforced alloys. Aluminium-metal matrix composite (AMC) materials having a lower density and higher thermal conductivity as compared to the traditionally used grey cast irons are expected to result in weight reduction of up to $60-65 \%$ in automotive parts [13].

Several works have been carried out on development Aluminium matrix composites (AMCs) in Nigeria. Adebisi et al [14] studied the effect of particle size of $\mathrm{SiO}_{2}$ on the properties of Al-Si particulates. Their results show that the use of fine particles have a higher degree of strengthening than the use of coarse reinforcement particles.

Maleque et al [15] stated that in composites, materials are combined in such a way as to enable one to make better use of their parent material while minimizing to some extent the effects of their deficiencies.

Aigbodion [16] studied the possibility of using kankara clay found in abundance in kankara village in Kastina state Nigeria as reinforcement for Al-Si-alloy. the result shows that kankara clay can serve as potential reinforcement for aluminium alloy up to a maximum of $20 \mathrm{wt} \%$ of this clay body in the alloy.

Amaren \& Aku [17] carried out an XRF analysis on Periwinkle shell ash and confirmed that $\mathrm{SiO}_{2}, \mathrm{CaO}, \mathrm{MgO} \mathrm{Cr}_{2}$ $\mathrm{O}_{3}$. and $\mathrm{Fe}_{2} \mathrm{O}_{3}$ were found to be major constituents of Periwinkle ash. The presence of hard elements like $\mathrm{SiO}_{2}, \mathrm{CaO}$, $\mathrm{MgO}, \mathrm{Cr}_{2} \mathrm{O}_{3}$. and $\mathrm{Fe}_{2} \mathrm{O}_{3}$ suggested that Periwinkle shell ash particles can be used as reinforcement material. 
Madakson et al [18] characterized coconut ash as a constituent of metal matrix composite for potential application in automobile sector. Microscopic (particle size, SEM and XRF) and spectroscopic analysis (XRD and FTIR) were carried out for characterization of the coconut shell ash.

Mostly, Aluminium motorcycle hubs are products of alloys of Al-Si-Mg because of their unique casting properties, good resistance to corrosion, easy to cast into thin or thick sections, excellent machinability, and a high strength-toweight ratio as compared to cast iron hub.

Ezatpour \& Sajjadi [19] revealed that the addition of $\mathrm{Al}_{2} \mathrm{O}_{3}-\mathrm{MgO}$ reinforcement to aluminium resulted to enhancement of hardness and strength of material.

Li et al [20] studied a Production Planning Model for Make-to-Order Foundry Flow Shop with Capacity Constraint. The results shows that the proposed approach can achieve better profit rate of orders in actual foundry industry more effectively.

\section{MATERIALS AND METHODS}

The materials used in this research includes:

- $5 \mathrm{~kg}$ of waste mango seed were obtained from Palladan and Samara Zaria Kaduna State Nigeria.

- The scrapped of convectional motorcycle hub containing Al-Si-Mg,

\subsection{Methodology}

Determine the Chemical Composition

Min pal compact energy dispersive X-ray spectrometer was used for elemental analysis of mango seed shell ash and the powder from the conventional motorcycle hub. Carbonization of mango seed shell ash was carried the following steps,

- The Mango seeds shells collected were dried in the sun for three days,

- Decorticated manually to remove the seed from the shell and grinded into powder.

- The powder of MSSA was packed in a steel box and carbonized in an air tightened condition using a furnace at $600^{\circ} \mathrm{C}$ for four hours.

- Sieved \& the particle size analysis carried out from $250 \mu \mathrm{m}$ to $106 \mu \mathrm{m}$

Development of the Composite through Stir Casting is a suitable way for manufacturing composites with up to $30 \%$ volume fractions. The stir casting was carried out according to standard casting procedures as shown in Figure. 2 below.

\section{Development of Composite Through Stir Casting:}

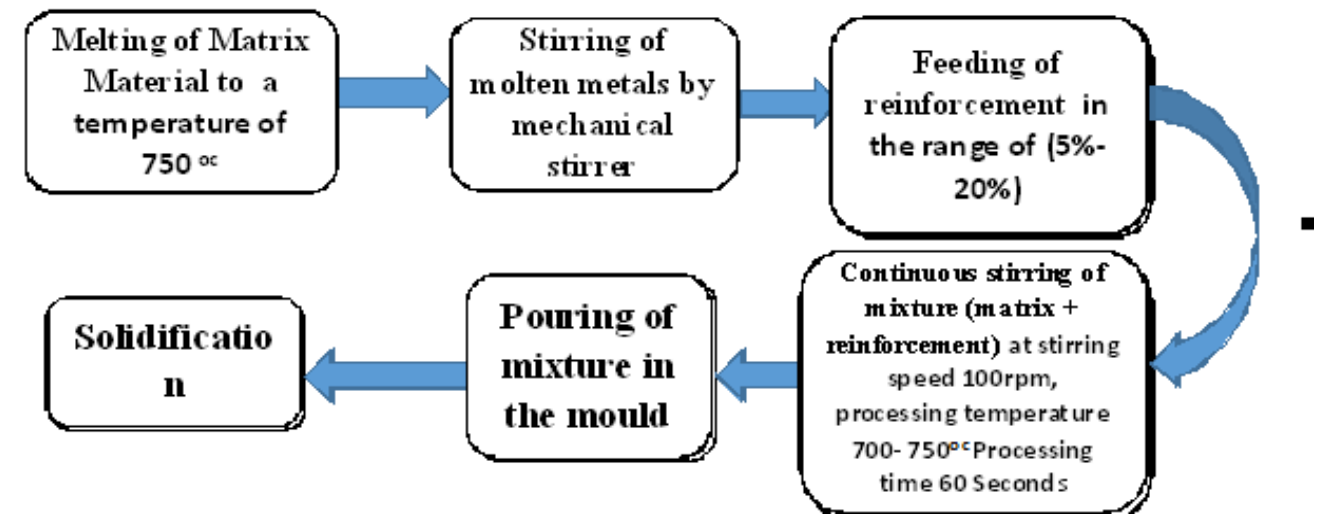

Figure.2: Casting procedures.

Table 1: charging of matrix and reinforcement into crucible furnace

\begin{tabular}{cccc}
\hline Casting Runs & \% Al-Si-Mg Alloy & \% MSSA & Samples No \\
\hline 81 & 100 & - & Control C \\
2 & 95 & 5 & A \\
3 & 90 & 10 & B \\
4 & 85 & 15 & D \\
5 & 80 & 20 & E \\
\hline
\end{tabular}




\subsection{Stir Casting Process}

A sand mold was prepared with diameter $30 \mathrm{~mm}$ and the length $80 \mathrm{~mm}$ and used to produce the test bars. The scrap motorcycle hub to be melted was first charged into the furnace and temperature was raised to $750^{\circ} \mathrm{C}$ to superheat the aluminium alloy melt. The $15 \%$ wt. of MSSA particle was pre-heated to $650^{\circ} \mathrm{C}$ to enhance wettability with the matrix. The pre-heated MSSA particles were added and stirred continuously for 60 seconds to achieve uniform distribution of the reinforcement by manual process at a stirring speed $100 \mathrm{rpm}$. The pouring temperature was controlled at about $720^{\circ} \mathrm{C}$. The crucible was removed from the furnace with special tongs was used as a ladle to pour into the prepared molds directly. After casting, the bars were machined to standard samples for mechanical tests.

\subsection{Determination of Hardness Value}

The hardness values of the cast samples were determined using a Vickers Hardness Testing Machine according to ASTM; E18-15 standards. The cast bars were machined to standard dimensional specifications of the test samples. The average reading of three different locations on the sample surfaces were taken in each case.

\subsection{Determination of Impact Strength}

The Impact strength was determined using the Charpy Universal Impact testing machine with specifications Hounsfield Balance impact machine serial No 3203, Total force capacity 48lb in the department of mechanical engineering, Ahmadu Bello University Zaria.

The sample were prepared with diameter of $8 \mathrm{~mm}, v$-notched to $0,5 \mathrm{~mm}$ depth from the middle with the total length of $46 \mathrm{~mm}$ according to standard of ISO 8256 (2004) for dent specified. The sample was fixed parallel between the stationary clamp and at a cross head of the pendulum hammer set to hit the cross head at the lowest point of the circular motion. The hammer speed was set at $1.5 \mathrm{~m} / \mathrm{s}$ which corresponded to the falling angle of 60 .

The specimen was broken by a single overload event due to the impact of the pendulum. A stop pointer is used to record how far the pendulum swings back up after fracturing the specimen. The impact toughness of a metal is determined by measuring the energy absorbed in the fracture of the specimen. This is simply obtained by noting the height at which the pendulum is released and the height to which the pendulum swings after it has struck the specimen. The height of the pendulum times the weight of the pendulum produces the potential energy and the difference in potential energy of the pendulum at the start and the end of the test is equal to the absorbed energy [15].

\subsection{Taguchi Experimental Design (Wear Test \& Tribological Analysis)}

Taguchi experimental Design was used to optimize the range of reinforcement of MSSA from 5\%wt-15\%wt in the Al- alloy matrix. Standard formula according to ASTM D 6079-97/EN 590 standards was used in examining the abrasive wear. The test samples were fabricated with a length of $35 \mathrm{~mm}$ and a diameter of $10 \mathrm{~mm}$ and were subjected to abrasive wear condition. The wear test of the composite was carried out using $0 \% w t, 5 \% w t .10 \% w t, \& 15 \% w t$ of MSSA, sliding speed of $5 \mathrm{~cm} / \mathrm{s}-20 \mathrm{~cm} / \mathrm{s}$, sliding distance from $50 \mathrm{~m}$ to $200 \mathrm{~m}$, and the load of $2 \mathrm{~N}, 4 \mathrm{~N}, 6 \mathrm{~N} \& 8 \mathrm{~N}$ respectively. The Wear testing machine used was Anton Paar GmbH Anton Paar Strasse $208054 \mathrm{Graz}-$ Austria in the faculty of Engineering Ahmadu Bello University Multi-user laboratory.

Taguchi Design L16 (4^4) Factors: 4 Runs: 16; The result of Taguchi Orthogonal Array Design L16 (4^4) Factors is shown in table 3. Evaluation of the impute process parameters based on based on Taguchi design. The result of Evaluation of the impute process parameters based on based on Taguchi L16 design. is shown in Table. Table 2 and Table 3 above provides adequate data required for tribological (wear \& friction) analysis.

Table 2: Taguchi L16 orthogonal array design

\begin{tabular}{ccccccc}
\hline & Factors & & 1 & 2 & 3 & 4 \\
\hline 1 & Load (N) & A & 2 & 4 & 6 & 8 \\
2 & Sliding Speed (m/s) & B & 5 & 10 & 15 & 20 \\
3 & Sliding distance (M) & C & 50 & 100 & 150 & 200 \\
4 & MSSA reinforcement (wt\%) & D & O (c) & $5(\mathrm{a})$ & $10(\mathrm{~b})$ & $15(\mathrm{~d})$ \\
\hline
\end{tabular}




\section{RESULTS AND DISCUSSIONS}

\subsection{Analysis of SN Ratio for Wear Rate}

From Table 4. the input functions with higher delta values have higher ranking and have more influence on the wear rate. Load. MSSA, Sliding Speed and Sliding Distance. (ADBC). (MSSA). A2 =4N, B2 = 10 cm/s C4=200m D4=15 wt\%. The optimum wear value will be obtained from the combination of Load $=4 \mathrm{~N}$, Sliding speed $=10 \mathrm{~cm} / \mathrm{s}$ sliding distance $=200 \mathrm{~m}$ and MSSA $=15 \mathrm{wt} \%$.

The Analysis of the result shows the optimum value is in the combination of Load $=4 \mathrm{~N}$, sliding speed $=10 \mathrm{~cm} / \mathrm{s}$ sliding distance $=200 \mathrm{~m}$ and $\mathrm{MSSA}=15 \mathrm{wt} \%$ These also correspond with the Analysis of wear maps \& wear rate diagrams displayed below.

Table 3: Evaluation of the impute process parameters based on based on Taguchi L16 design

\begin{tabular}{|c|c|c|c|c|c|}
\hline & A & B & C & D & $\begin{array}{c}\text { Wear rate } \\
(\mathrm{mm} / \mathrm{N} / \mathrm{M})\end{array}$ \\
\hline Sample & Load $(\mathrm{N})$ & Sliding speed $(\mathrm{cm} / \mathrm{s})$ & Sliding distance $(\mathrm{m})$ & MSSA Reinforcement (wt\%) & 0.04499 \\
\hline C1 & 2 & 5 & 50 & 5 & 0.02248 \\
\hline A2 & 2 & 10 & 100 & 10 & 0.01538 \\
\hline B3 & 2 & 15 & 150 & 15 & 0.02036 \\
\hline D4 & 2 & 20 & 200 & 10 & 0.03131 \\
\hline B5 & 4 & 5 & 100 & 15 & 0.01348 \\
\hline D6 & 4 & 10 & 50 & 0 & 0.01783 \\
\hline C7 & 4 & 15 & 200 & 5 & 0.02371 \\
\hline A8 & 4 & 20 & 150 & 15 & 0.01788 \\
\hline D9 & 6 & 5 & 150 & 10 & 0.01628 \\
\hline B10 & 6 & 10 & 200 & 5 & 0.05062 \\
\hline A11 & 6 & 15 & 50 & 0 & 0.03671 \\
\hline C12 & 6 & 20 & 100 & 5 & 0.01318 \\
\hline A13 & 8 & 5 & 200 & 0 & 0.01614 \\
\hline C14 & 8 & 10 & 150 & 15 & 0.02452 \\
\hline D15 & 8 & 15 & 100 & 10 & 0.04225 \\
\hline B16 & 8 & 20 & 50 & 0.01532 \\
\hline D17 & 4 & 10 & 200 & 5 & \\
\hline & & & & 5 & \\
\hline
\end{tabular}

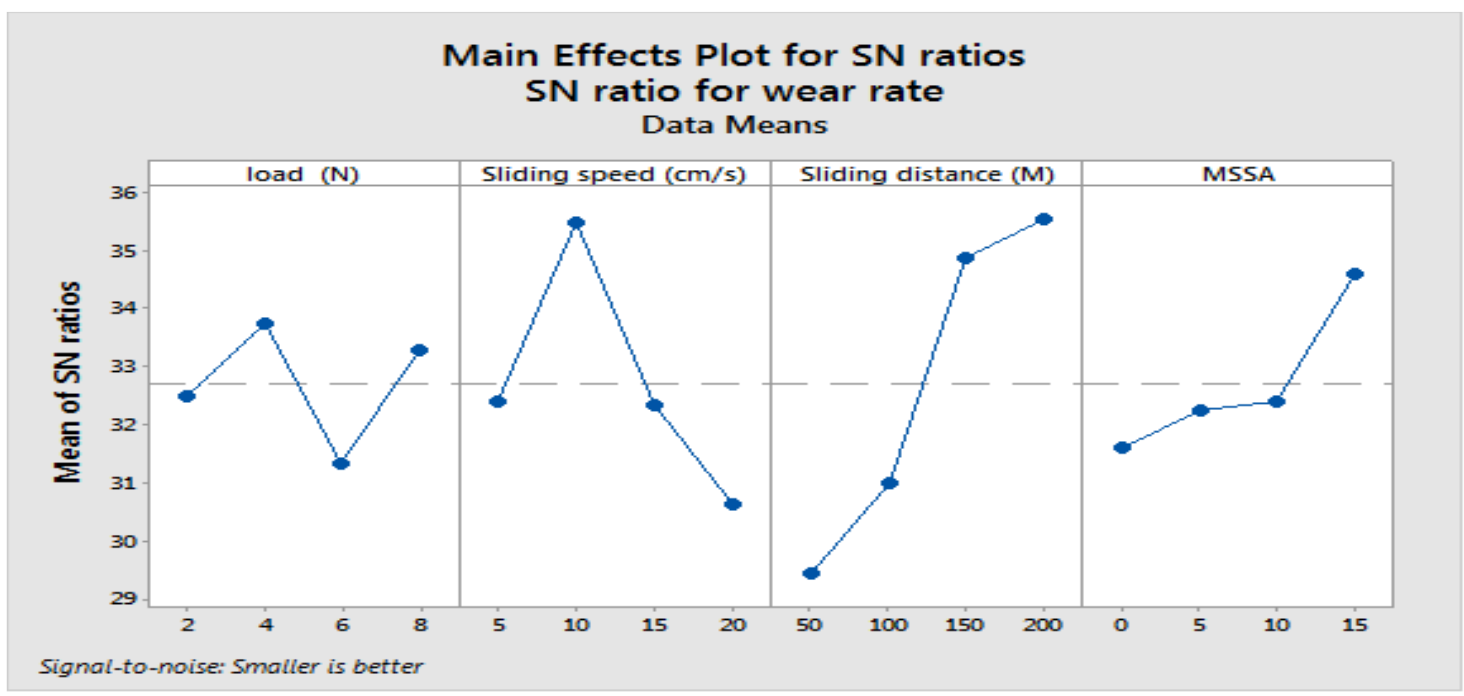

Figure 3: The $\mathrm{SN}$ ratio for the data means load, sliding speed, sliding distance and the mango seed shell ash 
Table 4: Analysis of SN ratio for wear rate

\begin{tabular}{|c|c|c|c|c|c|c|c|}
\hline \multirow{2}{*}{ Input function } & \multirow{2}{*}{ Symbols } & \multicolumn{4}{|c|}{ S/N Ratio } & \multirow{2}{*}{ Max-Min (delta) } & \multirow{2}{*}{ Rank } \\
\hline & & L1 & L2 & L3 & L4 & & \\
\hline Load & $A$ & 32.5 & 33.8 & 31.5 & 33.5 & 2.3 & 4 \\
\hline$S / S$ & B & 32.4 & 35.5 & 32.2 & 30.5 & 5 & 2 \\
\hline$S / D$ & C & 29.5 & 31.0 & 35.1 & 35.8 & 6.3 & 1 \\
\hline MSSA & $D$ & 31.2 & 32.0 & 32.1 & 34.9 & 3.7 & 3 \\
\hline
\end{tabular}

$A=\operatorname{Load}(N) B=$ sliding speed $(\mathrm{cm} / \mathrm{s}) C=$ sliding distance $(M) D=$ Mango Seed Shell Ash $W t \%$

\subsection{Analysis of Wear Maps \& Wear Rate}

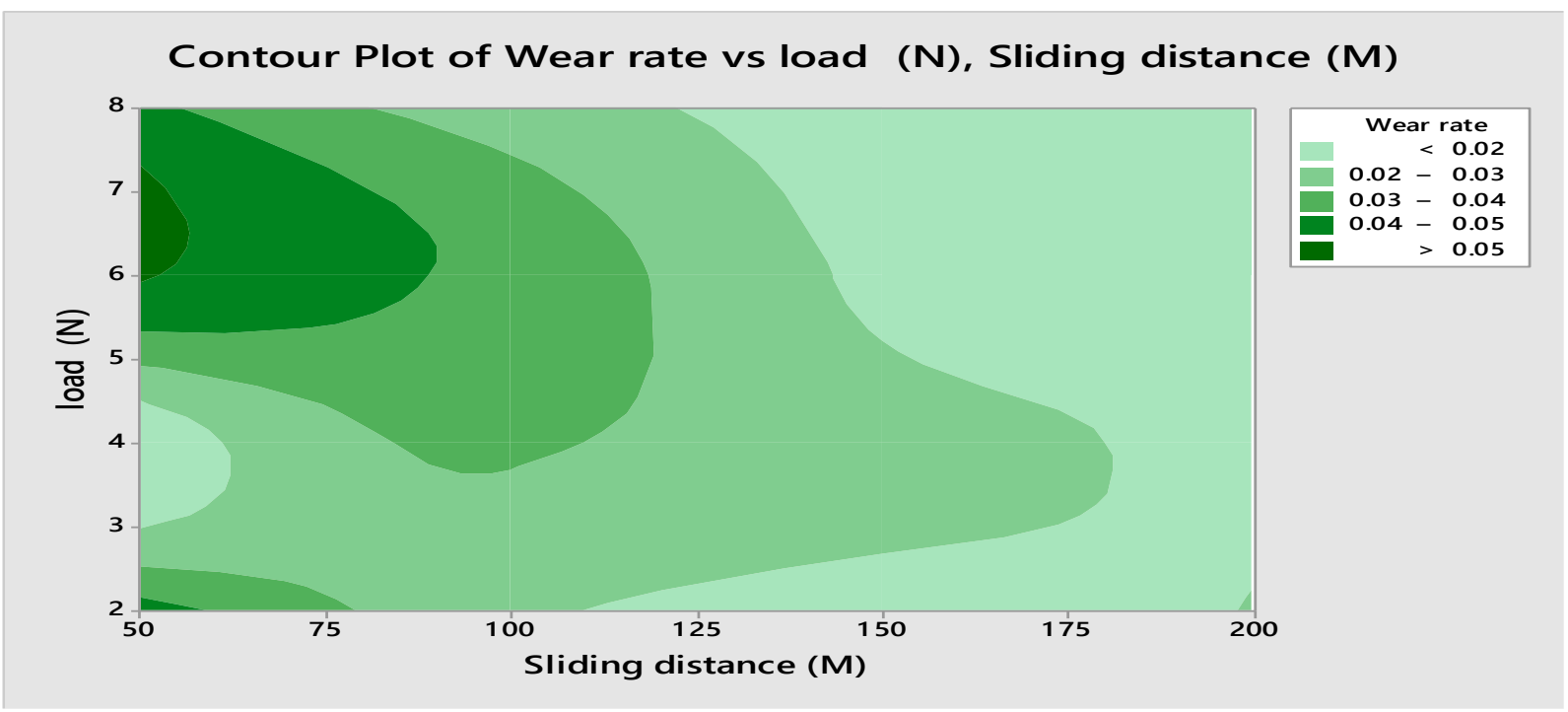

Figure 4: Wear Map 1 shows the lowest wear rate at sliding distance, 200m/s and the load of $4 \mathrm{~N}$

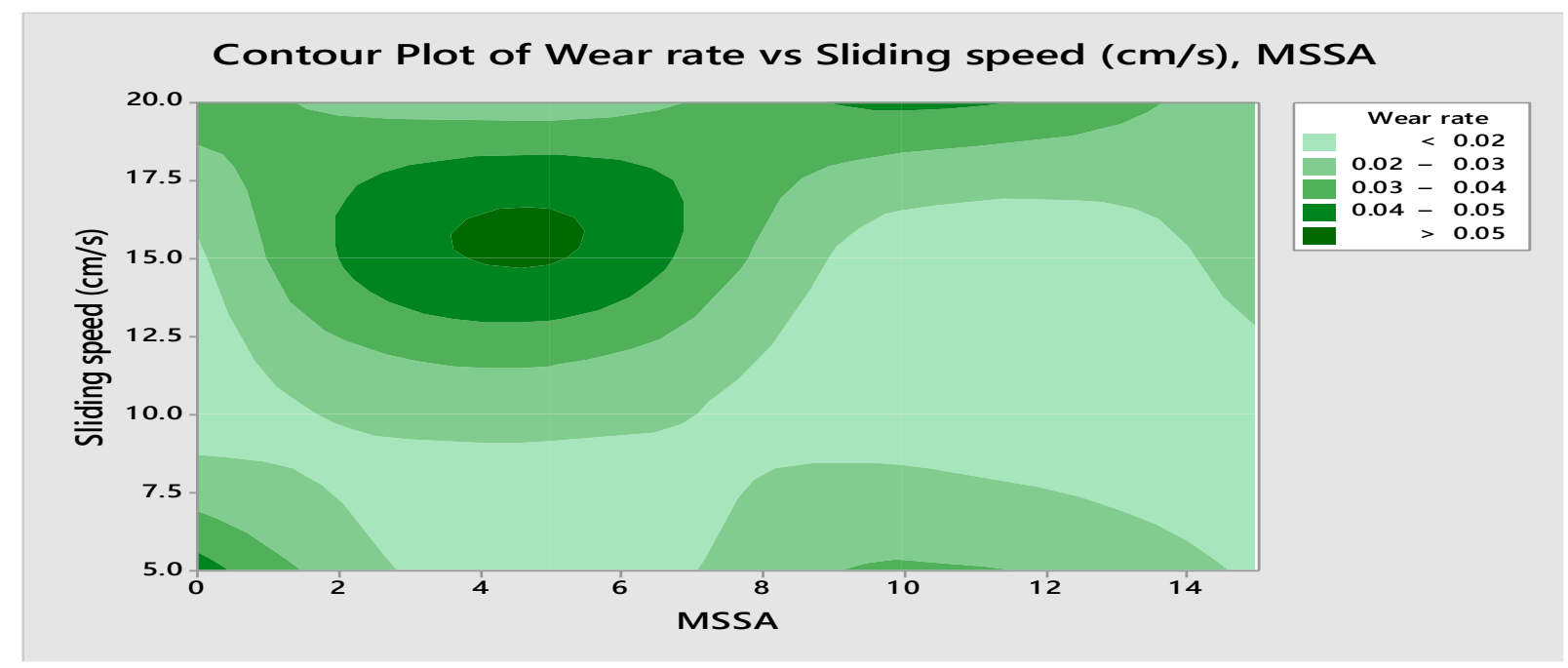

Figure 5: Wear Map 2 shows the lowest wear rate at sliding speed of $10 \mathrm{~cm} / \mathrm{s}$ and $15 \mathrm{wt} \% \mathrm{MSSA}$ 


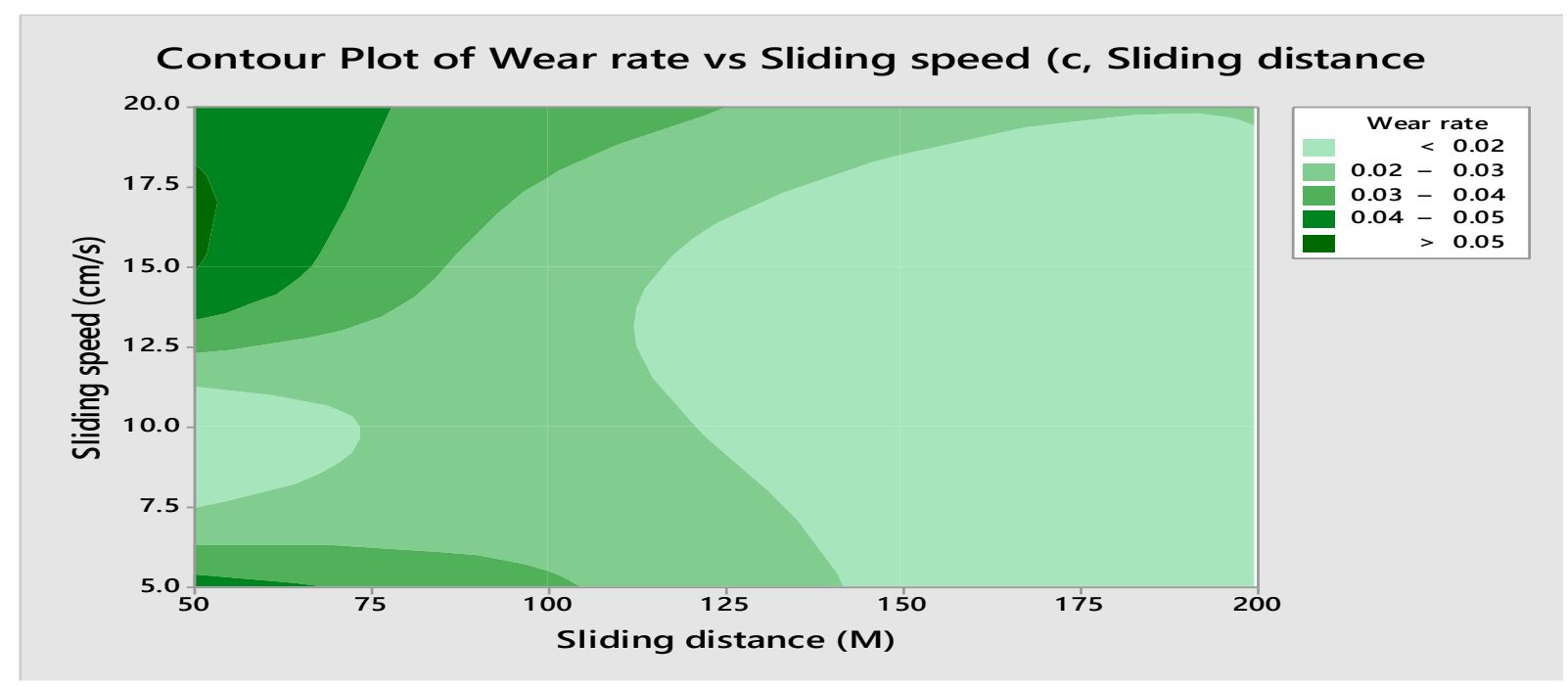

Figure 6: Wear Map 3 shows the lowest wear rate at sliding speed, $10 \mathrm{~cm} / \mathrm{s}$ and sliding distance, $200 \mathrm{~m}$.

\subsection{Morphology of Mango Seed Shell Ash (MSSA)}

Table 5 shows the result of X- ray fluorescent (XRF) pattern of mango shell ash (MSSA) which reveals that $\mathrm{SiO}_{2}$, has the highest percentage composition followed by $\mathrm{CaO}, \mathrm{Al}_{2} \mathrm{O}_{3}, \mathrm{Fe}_{2} \mathrm{O}_{3}, \mathrm{Mg}_{2} \mathrm{O}, \mathrm{K} 2 \mathrm{O}, \mathrm{ZnO}, \mathrm{Na}_{2} \mathrm{O}$ and $\mathrm{TiO}_{2}$, as major phases. The presences of these hard constituent compounds suggests that the mango seed shell ash can be used as particulate reinforcement in various metal matrices since the chemical composition has similarity with the XRF analysis of Periwinkle shell ash, rice husk, fly ash, and bagasse ash currently used in metal matrix composite. Amaren \& Aku [17], Aigbodion, and Hassan [1]. Si and Mg, enhances wettability and formation of $\mathrm{Mg}_{2} \mathrm{Si}$ and eutectic Si $\alpha$-Al matrix with MSSA particles. Therefore, they are attractive material for reinforcement of AMC for wear applications.

\subsection{Characterize of the Convectional Motorcycle Hub}

Table 6 shows the XRF pattern and elemental Composition of the convectional motorcycle hub. It reveals $\mathrm{Al}_{2} \mathrm{O}_{3}$, $\mathrm{SiO}_{2}, \mathrm{Fe}_{2} \mathrm{O}_{3}$ and $\mathrm{Mgo}$ as major phases. The elemental composition of silicon content is $6.55 \mathrm{wt} \%$ as reflected in Table 6. This is below the standard requirement for the Aluminium Alloy 356 (7\% Si) which is the popular alloy used for sand casting. This may account for the frequent wear and failure of the conventional Motorcycle Hub. The addition of MSSA which has content of silicon as particulate composite reinforcement may help address the problem of wear of the conventional motorcycle hub.

\subsection{Hardness Test}

Hardness values of Al-Si-Mg/ MSSA particulate composite with various percentage weight of MSSA loading is shown in Table 7. There is increasing trend of hardness strength with increase in weight percentage of MSSA up to $15 \%$ weight fraction. Beyond this weight fraction the hardness trend started decreasing as MSSA particles interact with each other leading to clustering of particles and consequently settling down. It is observed that the unreinforced alloy has the least hardness value of $31.9 \mathrm{HV}$ while at 15\% MSSA addition had the highest hardness value of $43.2 \mathrm{HV}$. This represents a $26.16 \%$ improvement over the convectional alloy. This indicates that there was good interfacial bonding between the matrix and the reinforcement.

Therefore, the optimized 15\% wt of MSSA reinforcement which has the best mechanical properties was selected for production of the hub. The increase in hardness is due to the presence of silicon particles formed because of reaction between the reinforcement MSSA particles and the molten Al-alloy matrix as well as other processing parameters. Factors such as non-uniform distribution of particles, cooling rate of the casting has affected the hardness value negatively hence there is no uniform hardness.

The result of impact energy of Al-Si-Mg/ MSSA particulate composite with various percentage weight of MSSA loading is shown in Table4.4. It is observed that the impact energy is lowest at 5\% MSSA while at 15\% MSSA addition had the highest hardness value of impact energy This indicates that there was good interfacial bonding between the matrix and the reinforcement. Beyond this weight fraction the impact energy trend started decreasing as MSSA particles interact with each other leading to clustering of particles and consequently settling down. 
Table 5: Elemental Composition of MSSA using (XRF)

\begin{tabular}{|c|c|c|c|}
\hline S/NO & ELEMENT & Concentration of oxide (wt\%). & Elemental composition (wt\%) \\
\hline 1 & $\mathrm{Na}_{2} \mathrm{O}$ & 2.302 & 1.708 \\
\hline 2 & $\mathrm{MgO}$ & 3.173 & 1.904 \\
\hline 3 & $\mathrm{Al}_{2} \mathrm{O}_{3}$ & 13.847 & 7.331 \\
\hline 4 & $\mathrm{SiO}_{2}$ & 43.574 & 20.334 \\
\hline 5 & $\mathrm{P}_{2} \mathrm{O}_{5}$ & 4.173 & 1.854 \\
\hline 6 & $\mathrm{SO}_{3}$ & 1.797 & 0.719 \\
\hline 7 & $\mathrm{Cl}$ & 0.467 & 0.464 \\
\hline 8 & $\mathrm{~K}_{2} \mathrm{O}$ & 4.559 & 3.783 \\
\hline 9 & $\mathrm{CaO}_{2}$ & 14.895 & 10.639 \\
\hline 10 & $\mathrm{TiO}_{2}$ & 2.129 & 1.277 \\
\hline 11 & $\mathrm{CrO}_{2}$ & 0.005 & 0.003 \\
\hline 12 & $\mathrm{Mn}_{2} \mathrm{O}_{3}$ & 0.130 & 0.091 \\
\hline 13 & $\mathrm{Fe}_{2} \mathrm{O}_{3}$ & 6.211 & 4.348 \\
\hline 14 & $\mathrm{ZnO}$ & 2.653 & 2.129 \\
\hline 15 & $\mathrm{SrO}$ & 0.089 & 0.075 \\
\hline
\end{tabular}

Table 6: Elemental Composition of Sample (motorcycle hub) using (XRF)

\begin{tabular}{|c|c|c|c|}
\hline S/NO & ELEMENT & Concentration of oxide (wt\%) & Converted to Element (wt\%) \\
\hline 1 & $\mathrm{Na}_{2} \mathrm{O}$ & 0.419 & 0.310 \\
\hline 2 & $\mathrm{MgO}$ & 1.014 & 0.608 \\
\hline 3 & $\mathrm{Al}_{2} \mathrm{O}_{3}$ & 82.117 & 43.474 \\
\hline 4 & $\mathrm{SiO}_{2}$ & 14.034 & 6.55 \\
\hline 5 & $\mathrm{P}_{2} \mathrm{O}_{5}$ & 0.000 & 0.053 \\
\hline 6 & $\mathrm{SO}_{3}$ & 0.133 & 0.455 \\
\hline 7 & $\mathrm{Cl}$ & 0.013 & 0.017 \\
\hline 8 & $\mathrm{~K}_{2} \mathrm{O}$ & 0.024 & 0.089 \\
\hline 9 & $\mathrm{CaO}$ & 0.124 & 0.03 \\
\hline 10 & $\mathrm{TiO}_{2}$ & 0.050 & 0.018 \\
\hline 11 & $\mathrm{Cr}_{2} \mathrm{O}_{3}$ & 0.026 & 0.115 \\
\hline 12 & $\mathrm{Mn}_{2} \mathrm{O}_{3}$ & 0.165 & 0.801 \\
\hline 13 & $\mathrm{Fe}_{2} \mathrm{O} 3$ & 1.144 & 0.59 \\
\hline 14 & $\mathrm{ZnO}^{2}$ & 0.736 & 47.323 \\
\hline 15 & $\mathrm{SrO}$ & 0.000 & 0.00 \\
\hline
\end{tabular}

Table 7: Variation of hardness property of the composite

\begin{tabular}{cc}
\hline$\%$ MSSA & Hardness Value (HV) \\
\hline Control C O\% MSSA & 31.9 \\
A 5\% MSSA & 33.63 \\
B 10\% MSSA & 42.9 \\
D 15\% MSSA & 43.2 \\
E 20\% MSSA & 36.5 \\
\hline
\end{tabular}


Table 8: Impact test results

\begin{tabular}{|c|c|c|c|c|c|}
\hline Samples & Diameter (mm) & Notch (mm) & $\begin{array}{c}\text { Energy } \\
\text { (lb. pounds) }\end{array}$ & $\begin{array}{c}\text { Average En } \\
\text { (pounds) }\end{array}$ & $\begin{array}{l}\text { Average } \\
\text { (Joules) }\end{array}$ \\
\hline $\begin{array}{l}\text { Control C. } 0 \% \\
\text { MSSA }\end{array}$ & $\begin{array}{l}10.3 \\
10.4 \\
10.0\end{array}$ & $\begin{array}{l}9.8 \\
9.4 \\
9.3\end{array}$ & $\begin{array}{l}2.2 \\
1.3 \\
1.5\end{array}$ & 1.66 & 2.251 \\
\hline A. $5 \%$ MSSA & $\begin{array}{l}10.0 \\
10.3 \\
10.5\end{array}$ & $\begin{array}{l}9.0 \\
9.4 \\
9.7\end{array}$ & $\begin{array}{l}0.5 \\
1.5 \\
1.0\end{array}$ & 1.0 & 1.356 \\
\hline B $10 \%$ MSSA & $\begin{array}{l}10.5 \\
10.5 \\
10.2\end{array}$ & $\begin{array}{c}9.9 \\
10.0 \\
9.6\end{array}$ & $\begin{array}{l}1.6 \\
2.0 \\
1.5\end{array}$ & 1.7 & 2.305 \\
\hline D 15\% MSSA & $\begin{array}{c}10.4 \\
9.8 \\
10.4\end{array}$ & $\begin{array}{c}9.8 \times v v g \\
9.7 \\
9.6\end{array}$ & $\begin{array}{l}2.0 \\
1.5 \\
1.9\end{array}$ & 1.80 & 2.440 \\
\hline E $20 \%$ MSSA & $\begin{array}{l}10.0 \\
10.0 \\
10.0\end{array}$ & $\begin{array}{l}9.3 \\
9.0 \\
9.4\end{array}$ & $\begin{array}{l}1.3 \\
1.0 \\
1.0\end{array}$ & 1.1 & 1.491 \\
\hline
\end{tabular}

$1 \mathrm{lb}=1.356 \mathrm{~J}$

\section{CONCLUSIONS}

The following conclusions can be drawn:

1. The result of XRF pattern of mango shell ash reveals the presence of hard constituent compounds like $\mathrm{SiO}_{2}, \mathrm{CaO}$, $\mathrm{Al}_{2} \mathrm{O}_{3}, \mathrm{Fe}_{2} \mathrm{O}_{3}, \mathrm{Mg}_{2} \mathrm{O}$. This suggests the possibility of mango seed shell ash particulate in metal matrix composite since the chemical composition has similarity with the XRF analysis of rice husk, fly ash, and bagasse ash currently used in metal matrix composite.

2. Addition of Mango Shall Ash particles to a conventional Al alloy used for production of motorcycle has resulted in micro-structural changes, it shows an increase of $26.16 \%$ hardness value over the as- cast Al-Si-Mg alloy used for conventional motorcycle hub which confirms that it can be used as a reinforcement material for Aluminium matrix composite.

3. The optimum hardness value was obtained at $15 \%$ wt of MSSA as particulate reinforcement, Similarly, the wear rate of the alloy was significantly improved at $15 \%$ wt of MSSA, load of $4 \mathrm{~N}$, Sliding speed $=10 \mathrm{~cm} / \mathrm{s}$ sliding distance $=200 \mathrm{~m}$.

4. By these results, it can be concluded that Mango Seed Shell Ash can be successfully added at $15 w t \%$ as reinforcement to Al-Si-Mg alloy for Production of Motorcycle hub hence providing the desired light weight, good mechanical, tribological and wear resistant properties and reducing the environmental problems created by them.

\section{REFERENCES}

1. Aigbodion, V. S. \& Hassan, S. B. (2010). Experimental correlations between wear rate and wear parameter of Al-Cu-Mg/Baggasse ash particulate composites. Material and Design, 31(4), 2177-2180.

2. Adebisi, A. A., Maleque, M. A. \& Rahman, M. M. (2011). Metal matrix composite brake rotors: Historical development and product life cycle analysis. International Journal of Automotive and Mechanical Engineering, 4, 471-480.

3. Panchiwa, J. A., Desai, D. A., \& Shah, P. (2015). Review on quality and productivity improvement in small scale foundry industry. International Journal of Innovative Research in Science Engineering and Technology, 4(12), 11859-11867.

4. Omotoyinbo, J. A., \& Oladele, I. O. (2010) Effect of plastic deformation and magnesium content on mechanical property of 6063 Aluminium alloys. Journal of Minerals and Materials Characterization and Engineering, 9(6), 539-546.

5. Kumar, S. A., \& Goud, R. R. (2021). Processing and characterization of 6061 aluminium alloy with nickel (Ni) and zirconium ( $\mathrm{Zr}$ ). Recent Trends in Mechanical Engineering, 353-361. Springer.

6. Sears, K. (1997). Automotive Engineering: Strategic Overview. 2(1): 55-68 Sumeet Wadibhasme, Amit Ladekar and Roshan Paunikar Hub Centre Steering. Discovery, 24(82), 29-32. 535 (2014). 
7. Zhu, L., Qui, F., Zou, Q., Han, X., Shu, S., Yang, H., \& Jiang, Q. (2021). Multiscale design of aAl, eutectic silicon and $\mathrm{Mg}_{2} \mathrm{Si}$ phases in Al-Si-Mg alloy manipulated by insitu nanosized crystals. Materials Science and Engineering, A 802, 140627.

8. Ikechukwuka, N. A. (1997). Characterization of Aluminium Alloy 2618 and its composites containing Alumina particles. PhD Thesis, Department of mechanical Engineering, University of Saskatchewan, Saskatoon; 1-24 Unpublished.

9. Padmanaban, S., Subramanian, R., Anburaj, J, Thillairajan, K. (2020). Rheo-die-casting of Al-Si-Mg/SiCp composite: Microstructure and wear behaviour. Materials Research, 23(2), 1-11.

10. Adebisi, A. A., Maleque, M. A. \& Ali, M. Y. (2015). Wear characteristics of multiple particle size silicon carbide reinforced aluminium composite. Advanced Materials Research, 1115, 174-177.

11. Surappa, M. K. (2003). Aluminium matrix composites: challenges and opportunities, Sadhana 28, Parts $1 \& 2$, 319-334.

12. Nturanabo, F., Masu, L., \& Kirabira, J. B. (2019). Novel applications of aluminium metal matrix composites. Aluminium Alloys and Composites. 71-92. IntechOpen. Edited by Kavian Omar Cooke.

13. Adebisi, A. A., Maleque, M. A. \& Shah, Q. H. (2014). Performance assessment of aluminium composite material for automotive brake rotor. International Journal of Vehicle Systems Modelling and Testing, 9(3-4), 207-217.

14. Adebisi, A. A., Maleque, M. A., Ali, M. Y. \& Bello, K. A. (2016). Effect of variable particle size reinforcement on mechanical and wear properties of $6061 \mathrm{Al}-\mathrm{SiCp}$ composites. Composite Interfaces, 23(6), 533-547.

15. Maleque, M. A., Adebisi, A. A., \& Izzati, N. (2017). Analysis of fracture mechanism for Al-Mg/SiCp composite materials. IOP Conf. Series: Journal of Materials Science and Engineering, 184, 012031.

16. Aigbodion, V. S. (2007). Particulate-strengthened of Al-Si alloy/alumino-silicate composite. Materials Science and Engineering: A, 460-461, 574-578.

17. Amaren, S. G. \& Aku, S. Y. (2013). Effect of periwinkle shell particle size on the wear behaviour of asbestos free brake pad. Results in Physics, 3, 109-114.

18. Madakson P.B, Yawas D.S, \& Apasi A. (2012). Characterization of coconut shell ash for potential utilization in Metal matrix composite for automobile applications. International Journal of Engineering Science and Technology, 4(3) 1190-1198.

19. Ezatpour, H. R. \& Sajjadi, S. A. (2013). Microstructure and mechanical properties of extruded $\mathrm{Al} / \mathrm{Al}_{2} \mathrm{O}_{3}$ composite fabricated by stir casting process. Transaction of Nonferrous Metals Society of China, 23(5), 1262-1268.

20. Li, X., Guo, S., Liu, Y., Du, B., \& Wang, L. (2017). A production planning model for make-to-order foundry flow shop with capacity constraint. Mathematical Problems in Engineering, 6315613. https://doi.org/10.1155/2017/6315613. 